\title{
Okoshi-ezu: Speculations on thinness
}

\section{Andrew Barrie}

\section{Introduction}

In a recent monograph on the architecture of Toyo Ito, eminent philosopher and architecture critic Koji Taki made use of a striking analogy - he described Ito's Tod's Omotesando Building (2004) as being as if "the entire volume were wrapped in a single sheet of paper" (Taki 2006: 9). The aesthetics of thinness and ephemerality have long been central to Ito's work, and the image of paper is something Ito himself used early in his career. In an essay entitled The Thin Façade Ito described the façade of the one of his key projects from the 1970s, the PMT Building in Nagoya (1978), as being "like a curved sheet of paper" (Ito 1978a: 21).

Some commentators have extended - perhaps speculatively - this notion of paper-like thinness in Ito's architecture, noting a similarity in his work to an ancient Japanese drawing technique called okoshi-ezu, or "folding drawing", that is little known in the West. In an essay on the work of David Chipperfield written in the early 1990s, Kenneth Frampton made a passing and rather cryptic reference to the use of two-dimensional planes in Ito's architecture as an "aestheticized play on the okoshi-ezu tradition" (Frampton 1992: 11), and I too have previously noted similarities to okoshi-ezu in Ito's more recent work (Barrie 2004).

The intriguing thing about Taki's "sheet of paper" analogy in relation to the Tod's Building (Fig. 1) is that it came at a time when Ito seemed intent on jettisoning notions of emphemerality. Since completing work on the Sendai Médiathèque in 2001, Ito's work underwent a fundamental shift:

My aim used to be to transcend Modernist architecture by means of lightness and transparency. However, I have begun to feel that ... I may be able to arrive at a more convincing scheme by trying to express, not lightness or transparency, but strength. (Ito 2005: 16)

How, then, should we understand the continuing paper-like qualities of Ito's recent work? This paper traces the emergence of the okoshi-ezu technique in the Edo period (1603-1868), examining its unique representational qualities. It then addresses the claims that Ito's architecture is directly influenced by the okoshiezu tradition, and uses the okoshi-ezu as a vehicle by which to speculate about the particular surface-oriented qualities of the Tod's Omotesando Building and several of Ito's other post-Médiathèque projects.

\section{A systematic architecture}

In Edo period Japan, construction was a highly constrained affair. Building work was carried out by family-based carpentry workshops. In contrast to modern 


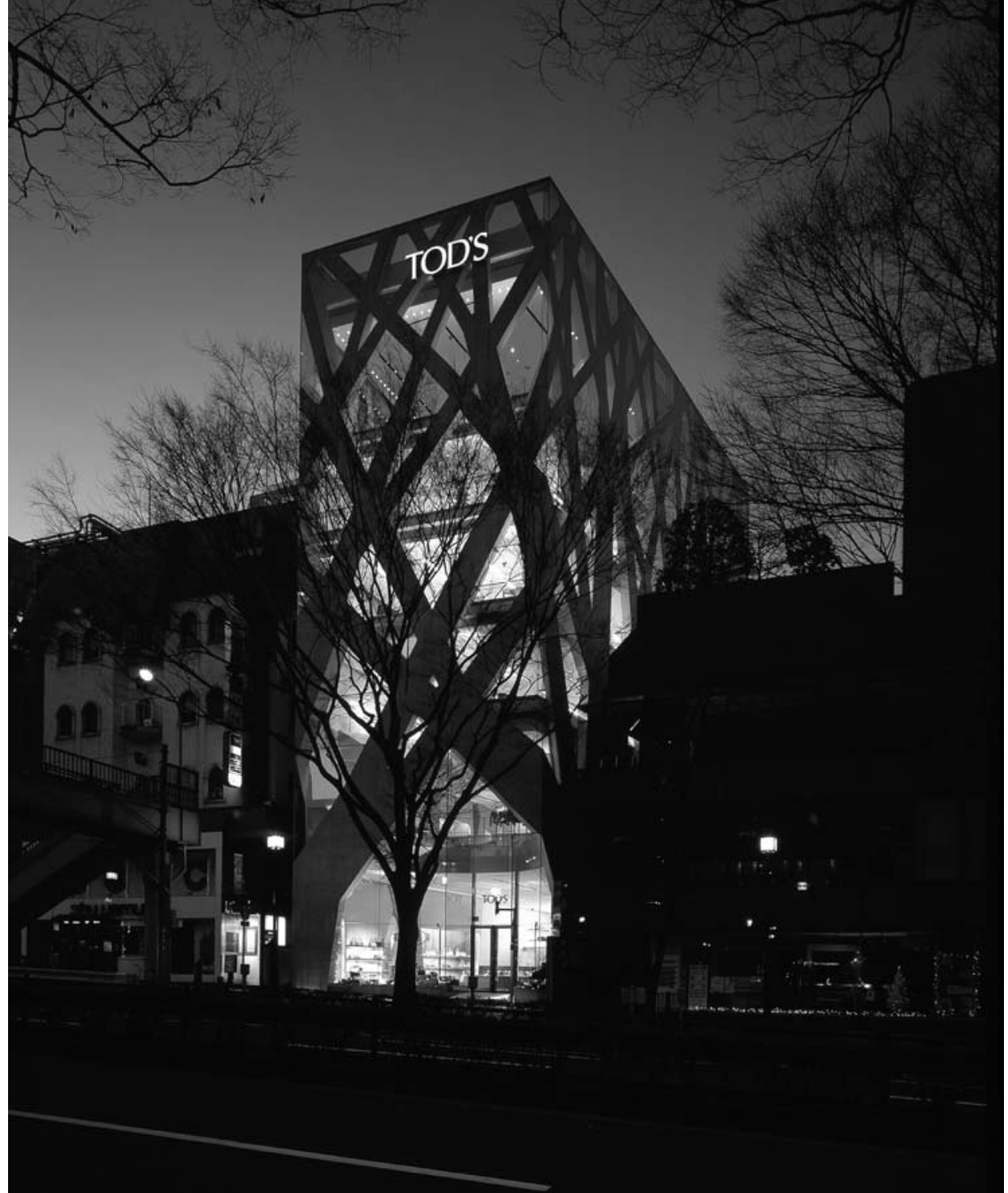

practice, which clearly separates the roles of designer and builder, the Japanese master carpenter performed both the development of the design and the supervision of the construction process. These families of carpenters, much like the stonemasons guilds of medieval Europe, designed and executed their buildings in a seamless process (Coaldrake 1990: 14).

Building design, however, was determined more by conventions and practical constraints, such as the way wood could be split or cut, than by the arbitrary design intentions of the carpenter. These conventions were embodied in the systems of proportions and modules that guided traditional practice. Based on a few simple modules such as the thickness of columns or the width of structural bays, the dimensions of each building element related to those of every other. Although drawing techniques evolved over time, for the most part Edo-period construction drawings consisted only of simple plans (Okawa 1975: 114). Elevations and detail drawings were sometimes also prepared, but the detailed design of the building was largely determined by experience and the use of the proportion systems.

The transmission of specific techniques within each carpentry workshop was shrouded in secrecy, with knowledge and traditions being passed on through master-apprentice relationships. To record the "cumulative wisdom and experience of successive generations of carpenters", manuals and pattern books had begun to be produced in the fourteenth century (Coaldrake 1990: 38). They were not "how to" books explaining basic carpentry techniques, but described in written and diagrammatic form the various plan types and proportional systems which formed the basis of building design. The earliest books were passed down
Fig. 1 The Tod's Omotesando Building, Tokyo (2004). Photo: Nacasa \& Partners Inc. Courtesy Toyo Ito $\mathcal{E}$ Associates, Architects. 


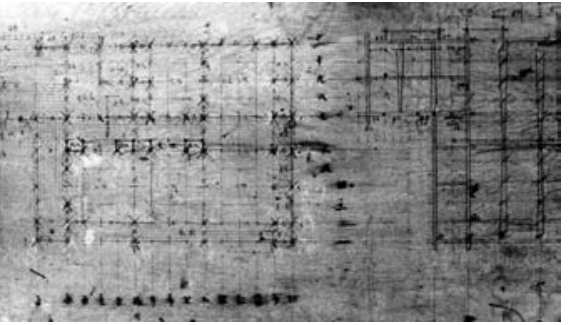

Fig. 2 The plan board. Courtesy William H. Coaldrake.

Author's note: this paper revisits and further develops material from my DEng thesis (Barrie 2003).

I There is some disagreement among scholars as to whether okoshi-ezu were used during design or simply served to record existing buildings. The difficulty is that although the okoshi-ezu method seems to have originated early in the Edo period - exactly when or how is not clear - the oldest surviving examples date from the latter part of the Edo period. See Nakamura (1998: 30-31). It is argued here, however, that the detailed and customised designs of sukiya architecture would not have been possible without a design tool such as the okoshi-ezu. from generation to generation, although by the Edo period the expanding use of woodblock printing techniques meant that manuals were becoming widely available. This dissemination of advanced techniques and high-culture styles elevated the general quality of building. However, by establishing clear architectural design standards these books stifled innovation and individuality (Nishi \& Hozomi 1983: 47). This standardisation was reinforced by detailed regulations laid out by the feudal government. Called "sumptuary laws", these rules set out the styles, construction methods, materials, and even the number and arrangement of rooms that were permitted for members of the various strata within each social class.

The effect of all these layers of constraint was that a practiced builder could visualise and construct an entire building using just a plan board and his measuring tools. The plan board was a simple, diagrammatic plan drawn in ink on thin pieces of board (Fig. 2). It indicated pillars, flooring, verandas and steps, as well as the location and type of wall openings. As the design of the building was determined by customary modules, the plan board included only a minimum of dimensions or other written notes. In addition to the plan board, carpenters also made use of various squares and a long rod for measuring and marking the elements of the building. These tools were particularly important for working in the vertical plane, and they effectively filled the role that might otherwise be performed by section and elevation drawings (Itoh 1972: 42).

\section{Escaping the grid}

Naturally, construction techniques in Japan had developed considerably over the centuries, many of the changes being brought about by the advent of new tools and woodworking methods. By the start of the Edo period, however, the development of temples and shrines had largely stopped, and the sumptuary laws inhibited the evolution of residential architecture. The ruling elite, however, created certain types of building in which the predetermined patterns were set aside and innovation was encouraged, notably those built in the sukiya style. These developing types included castles and aristocratic residences, but the most important influence on sukiya architecture was the teahouse (Itoh 1972: 26). These small spaces were intended to create a heightened sense of awareness in their occupants, and their design and construction demanded intense consideration and attention to detail. The position and height of windows, the arrangement of the alcove, hearth and other features, the selection of materials and textures, and the details of fabrication were all carefully manipulated by the designer. In order to consider and communicate such detailed and specific design intentions, a new type of drawing emerged - the okoshi-ezu or "folding drawing". Such a sophisticated tool had not existed before. ${ }^{1}$

Okoshi-ezu (or tateokoshi-ezu or tate-ezu) were "pop-up" drawings which folded up to create a fully three-dimensional miniature. They consisted of pieces of washi paper cut to the shape of walls fixed onto a plan drawing. Holes were cut into the walls for windows and openings, and minor elements such as shutters, raised floors and steps were sometimes fixed into place on the walls. Drawn onto both sides of the paper walls were the various elements of the room - structural members, windows, fusama, shoji, shelves, fittings, and so on. Particular attention was paid to the patterns of bamboo, reeds and vines used in windows and as ceiling linings, to the shape of rough-hewn timbers, and also to the size and placement 

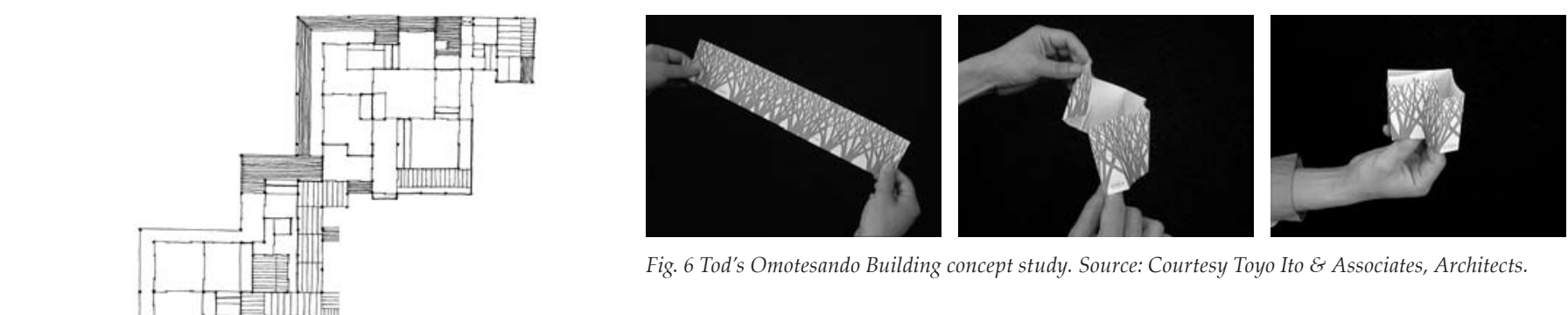

Fig. 6 Tod's Omotesando Building concept study. Source: Courtesy Toyo Ito \& Associates, Architects.

designed spaces without predetermined relationships to each other (Itoh \& Futagawa 1969: 84). ${ }^{2}$ Itoh suggests that the sukiya buildings were the first in the history of Japanese architecture to be conceived through the addition of individual rooms rather than through the subdivision of a larger whole. This is clearly seen at the famed Katsura Detached Palace in Kyoto (1616-60), which is composed as a loose collection of rooms arranged in a staggered plan (Fig. 5). Thus, in terms of planning, sukiya architecture represents a shift to the priority of space over

Fig. 5 Plan of Katsura Detached Palace, Kyoto.

2 In minka, argues Itoh, the layout of spaces in the house was determined by the position of the columns that supported the roof structure. Columns normally appeared at the corners of rooms, with sliding partitions arranged between them to subdivide the total floor space. Sukiya architecture, however, had no such basic framework, and Itoh asserts that it was only after the floor plan had been determined - as an assemblage of individually designed rooms - that the problem of supporting the roof was addressed. In short, the fundamental difference was that "in the minka style the structure restricts the floor plan, while in the sukiya style the floor plan restricts the structure." (Itoh \& Futagawa 1969: 84) structure as the organising principle of the design. In contrast to spatial uniformity of the earlier styles, sukiya architecture was intended to allow the creation spatial variety. Okoshi-ezu served as a tool for both determining and recording such highly customised and specific designs.

With its cutout paper walls and floor, the okoshi-ezu technique presents the elements of the building as thin planes. While this might be seen as a coincidental effect of the drawing's paper material, this does in fact reflect the building's physical reality. In earlier architectural styles, the thickness of the main loadbearing columns was about $300 \mathrm{~mm}$, while sukiya columns were typically about 120mm (Itoh \& Futagawa 1969: 84). Thus, sukiya buildings were literally "thinner" than comparable buildings in earlier styles.

The okoshi-ezu has no real counterpart in Western drawing. A rarely used technique from England employed folding paper elements - flaps were attached to presentation drawings to allow the patron to consider alternative solutions, for example, in the plan or ornamentation (Wilton-Ely 1977: 181-182). However, where the okoshi-ezu provides information from a different dimension (i.e. adding the vertical dimension to the horizontal plan), these drawings introduce images of an alternate reality. Perhaps the okoshi-ezu's closest Western analogue is the "developed surface interior", which was used to represent domestic interiors for a rather brief period in the late eighteenth century (Evans 1997: 202). But where the conceptual folding down of these drawings fractured the space represented, the literal folding up of the okoshi-ezu creates a spatial unity.

Okoshi-ezu are extraordinary in that they are both easy to understand and extremely comprehensive - a combination that is usually mutually exclusive in architectural drawing, where legibility tends to decline as the density of information increases. This quality makes okoshi-ezu drawings extremely helpful in studying the buildings they represent. Indeed, okoshi-ezu provided such a complete description of the design that they were often used as the basis for the common practice of copying teahouses; the dimensional and specification information they included meant they could be used as construction drawings. These drawings could communicate so much with so little because their representational qualities were so similar to the actual architecture they represented - thin walls wrapped around cubic spaces to create highly refined and specific compositions of material, space, and light. 


\section{Toyo Ito and okoshi-ezu?}

The okoshi-ezu drawing technique is little known outside Japan but is familiar to most Japanese architects, being mentioned in many books on tea culture and its architecture (Nishi \& Hozomi 1983; Nakamura 1998; Hayashiya et al 1974). The technique has, however, only rarely been employed in the service of contemporary architecture, most notably by Arata Isozaki in the 1970s in his explication of the somewhat contested Japanese notion of ma space (Matsuoka 1978), and by Takefumi Aida to represent some of his early houses (Aida 1984; Bognar 1990), although Aida's drawings explicitly represent the thickness of walls and therefore more closely resemble volumetric paper cut-out models than the fold-up okoshi-ezu drawings. ${ }^{3}$

Aida's drawings were included in the exhibition catalog, A New Wave of Japanese Architecture, edited by Frampton (1978: 15-19). This book also included Ito's PMT Building, as well as an essay by Ito in which he once again described the elements of his buildings as being "treated lightly and graphically as if they were made of paper" (Ito 1978b: 69). It was perhaps this juxtaposition of the okoshi-ezu technique with Ito's comments that prompted Frampton to casually assert that Ito had been influenced by the "okoshi-ezu tradition" in his 1992 essay (1992: 11). Commentators discussing contemporary Japanese buildings frequently position them in relation to traditional Japanese patterns, and are often tempted to assert some kind of continuity between the two. However, questioned directly about okoshi-ezu, Ito disavows any such influence on his work (Ito 2010b). He points out that in early works such as the PMT Building, the House in Nakano (1977) and Hotel D (1978), his interest was simply in expressing "thin outer surfaces" (Ito 1978a: 21). Frampton, it seems, has assumed a relation of causality when there was only correlation; the connection between the thin planes of Ito's buildings and the okoshi-ezu is simply one of resemblance.

However, if Frampton went one step too far, the paper-like qualities he identified in Ito's early work were validated by the architect's own words, and the same qualities noted by Koji Taki in relation to the recent Tod's Building remain striking. This is particularly apparent given the much-published conceptual image of the Tod's Building - which likely influenced Taki's comments - that show the façade as a patterned paper strip folded to define the building's perimeter wall (Fig. 6). Similar drawings exist for several other recent Ito projects: developed surface drawings show the structure passing across the surface of the roof and walls of the Serpentine Pavilion in London (2002), and unfolded elevations described the patterned façade of the MIKIMOTO Ginza 2 building in Tokyo (2005).

While Ito doesn't use the okoshi-ezu technique per se, it is clear that the conception of some of his buildings does follow a very similar kind of thinking - buildings defined by thin and highly-graphic folded planes. The last section of this paper will explore this relationship of resemblance, examining the Tod's Building and other of Ito's post-Médiathèque works alongside the okoshi-ezu technique and offering some speculations as to the significance of the surface-oriented character they have in common.

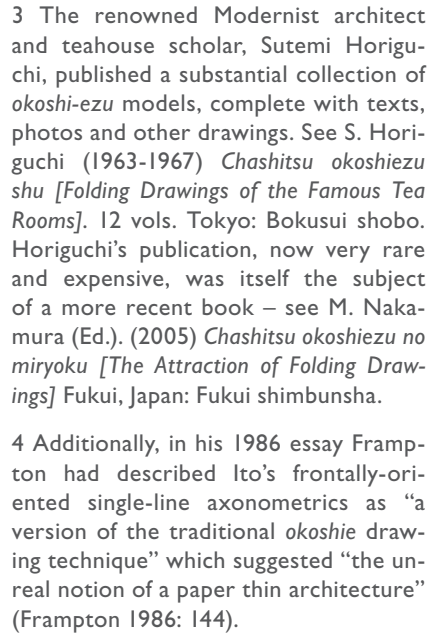

3 The renowned Modernist architect and teahouse scholar, Sutemi Horiguchi, published a substantial collection of okoshi-ezu models, complete with texts, photos and other drawings. See S. Horiguchi (1963-1967) Chashitsu okoshiezu shu [Folding Drawings of the Famous Tea Rooms]. 12 vols. Tokyo: Bokusui shobo. Horiguchi's publication, now very rare and expensive, was itself the subject of a more recent book - see M. Nakamura (Ed.). (2005) Chashitsu okoshiezu no miryoku [The Attraction of Folding Drawings] Fukui, Japan: Fukui shimbunsha.

4 Additionally, in his 1986 essay Frampton had described Ito's frontally-oriented single-line axonometrics as "a version of the traditional okoshie drawing technique" which suggested "the unreal notion of a paper thin architecture" (Frampton 1986: 144) 


\section{A new architecture}

Ito's writings and interviews since the completion of the Médiathèque have been characterised by his increasingly boldly-stated desire to move "beyond modernism" (Ito 2006: 32); one recent interview characterised his current position as an "anti-Mies stance" (Ito 2010a: 302). Ito takes particular aim at the role of the grid, which he sees as the "architectural order of the twentieth century" (Ito 2009: 7). For Ito, the grid defines the contemporary city as uniform or homogenous space, which in turn has a homogenising effect on society and on its individual members. Defining the grid as the cause of society's ills is clearly an oversimplification, but it provides a clear architectural direction to explore. Ito states his goal is now to "transform homogenous space" (Ito 2009: 8), and suggests that in this task "structure offers important clues" (Ito 2006: 32).

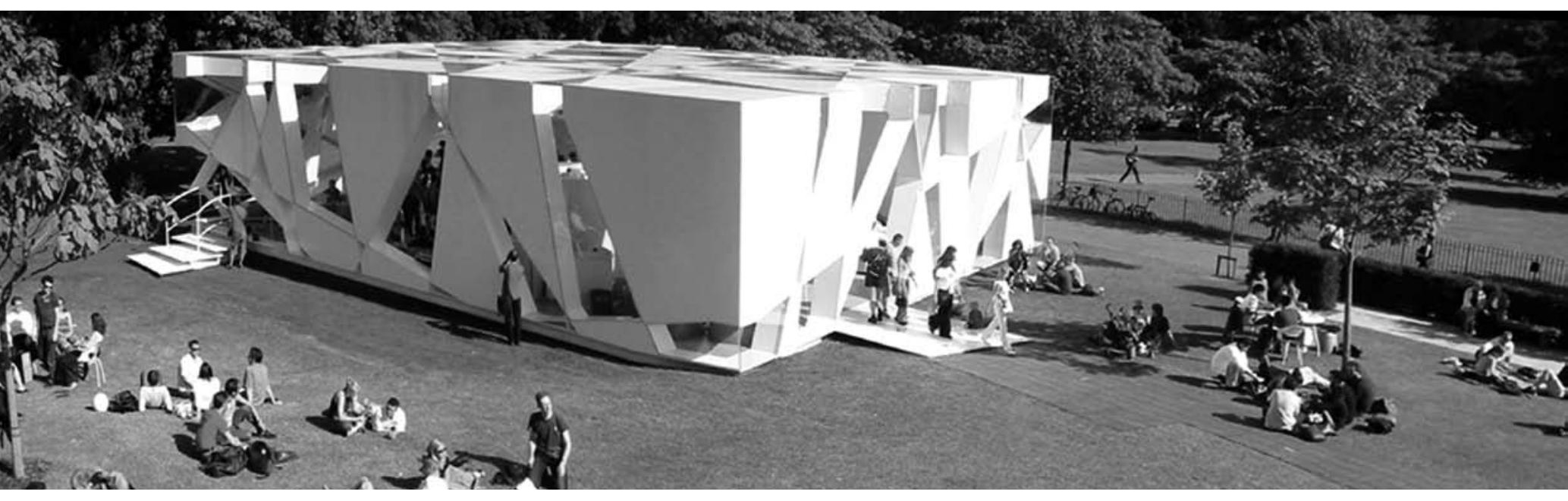

Fig. 7 The Serpentine Pavilion, London (2002). Source: Courtesy Toyo Ito $\mathcal{E}$ Associates, Architects.
In the wake of the Médiathèque's completion, Ito described a lingering dissatisfaction with its design. While the vertical structure of the tubes was organic and free, the flat floor slabs they passed though implied a certain uniformity. The building, he complained, had "been assembled from elements with opposing tendencies. Will a time come when I am liberated from this contradiction?" (Ito 2001: 7) In subsequent projects, his attention focussed therefore on developing structural systems that didn't consist of distinct systems for horizontal and vertical dimensions - that is, structural systems that were three-dimensionally integrated.

This search focussed, it is argued here, on continuity as an alternative to separation. The early Modernists, seeking to escape the limitations imposed by the heavy masonry structures which characterised the European architecture of the time, separated the structural and space-defining elements of their buildings; this separation made possible the independent manipulation of structure, façade and internal partitions that was fundamental to Le Corbusier's dom-ino system. Looking to attack the homogenising influence of the dom-ino structural grid, Ito sought to reunite what the moderns split asunder: "For 100 years Modern Architecture has been created by separating the structure from the external envelope, but my intention is to reunite them" (Takiguchi 2005). In this task, Ito followed the Moderns in making use of the new materials and the new methods of structural analysis of his time, but in re-integrating structure and envelope with the aim of creating new ways of building he effectively reversed Modernist innovations. 
Ito achieved his goal in two small but startlingly-original projects completed soon after the Médiathèque: the Bruges Pavilion in Bruges, Belgium (2002) and the Serpentine Pavilion in London (2002). ${ }^{5}$ In many ways these buildings were very simple, formed from structurally patterned folded planes. The use of the fold is a relatively common compositional or organisational device in contemporary architecture; what was unique in these buildings is that they consisted of the folded surface and literally nothing else. Further, the structures of these buildings, were remarkable in being non-hierarchical. The walls and roof of Ito's Serpentine Pavilion, for example, employ exactly the same structure; the structural system acknowledges difference only in the most subtle way, in that the thickness of each steel plate has been determined by the specific loads it carries (Fig. 7). Even distinctions such as those usually made between primary and secondary structural elements had disappeared.

The remarkable purity and clarity of these pavilions was made possible by their programmatic simplicity and relatively small size. In the larger and more complex Tod's Omotesando Building and the MIKIMOTO Ginza 2 project in Tokyo (2005), structure and envelope remained integrated but distinctions between horizontal and vertical structure re-emerged; both were defined by thin, continuous perimeter walls which became "both graphic pattern and structural system" (Ito 2009: 194).

This mode of design seeks to resolve all the structural, spatial and functional requirements of the project in one stroke. Each building has been distilled into an all-encompassing system, which often involves dispersing the various functions of the building - load-bearing, weathertightness, lighting, insulation, storage, ventilation - throughout the building's structure. Each part is related to every other. The unity of the various systems was created by the use of algorithms or rules to generate a spatial or structural geometry. These rules were not highly sophisticated; at the Tod's Building, the structure was defined by the repetition of the silhouette of a simple tree. The goal, however, was not uniformity, but the opposite - the creation of spatial variety, such that each spot within a building has its own character. The varying thickness and density of the branches in the Tod's tree silhouette results in each floor having a different spatial character, fulfilling Ito's desire for non-homogenous space (Fig. 1). These architectural systems are capable of generating three-dimensional complexity, variety and, in many cases, apparent randomness, while maintaining a sense of both economy and clarity. Integrating structure and envelope disguises the elements we normally understand as structural. This suppression of the force of gravity creates the appearance of effortlessness.

The Modernist preference for separation allowed each element of a building whether tectonic, functional or spatial - to be (or at least appear) identifiable and self-contained. But where modernism resulted in an architecture of parts, Ito's re-integrated emergent architecture is one of continuity. There is nothing apart from the continuous, effortless surface. It is this continuity, the compression of all the architectural action into the building's surfaces to create a highly graphic effect, that, it is argued here, explains why these buildings so strongly resemble the three-dimensionally arranged paper sheets of the okoshi-ezu technique.
5 This line of development also includes the Aluminium Cottage in Yamanash (2004), and the SUMIKA Pavilion in Utsunomiya (2009). These two buildings fit less comfortably, though, as, due to the inclusion of "non-surface" elements - partition walls in Yamanashi and columns in Utsunomiya - they are less pure as non-hierarchical systems. 


\section{Conclusion}

6 It's important to note that the resemblance proposed is between Ito's buildings and okoshi-ezu models, not between Ito's buildings and sukiya designs. Intriguingly, however, both Ito's recent work and sukiya architecture hold in common a shift from the grid to freer or more variable or flexible organisational principles.
The teahouses depicted by Edo-period okoshi-ezu could not be rotated - the wall could not become the floor, nor the ceiling the wall. But in the okoshi-ezu drawings these distinctions were erased and the various elements were represented in the same way - as uniformly thin planes. ${ }^{6}$ We can see in Ito's new architecture a drive towards a physically lighter or thinner architecture, and a desire to escape the universal space of the grid for greater variety and specificity. The similarity of these buildings to okoshi-ezu drawings is in part due to their thinness and, in some cases, their whiteness, but by configuring his buildings as three-dimensional compositions of uniform, highly patterned structural planes, Ito has created buildings that resemble these drawings to an extraordinary degree.

The paper-like qualities of Ito's architecture, however, may be undergoing an important shift. While many of Ito's recent projects have employed continuous surfaces as structure, he has moved increasingly beyond planar, folded surfaces. The Relaxation Park in Torrevieja, Spain (2001-) and the Taichung Metropolitan Opera House in Taiwan (2005-) take the form of three-dimensionally curved shell structures. It seems the use of complex, organic geometries will allow Ito's structures to retain their thinness but jettison the fragility suggested by paperlike planes, fulfilling Ito's twenty-first-century desire to make architecture that expresses strength.

\section{References}

Aida, T. (1984). Kenchiku nouto aida takefumi: tsumiki no ie [Architecture Note Takefumi Aida: Toy Block House]. Tokyo: Maruzen.

Barrie, A. (2003). Folded Space: The Representation of Space in Edo Era Architectural Drawings and Cartography. [Edo jidai kenchiku zumen to chizu ga kataru kukan.] Unpublished Dissertation for the Degree of Doctor of Engineering, University of Tokyo, Tokyo.

Barrie, A. (2004). Tracing Paper. Monument (64), 38-44.

Bognar, B. (1990). Takefumi Aida: Buildings and Projects. New York (NY): Princeton Architectural Press.

Coaldrake, W. H. (1990). The Way of the Carpenter: Tools and Japanese Architecture. New York (NY) \& Tokyo: Weatherhill.

Evans, R. (1997). The Developed Surface: An Enquiry into the Brief Life of an Eighteenth Century Drawing Technique. In R. Evans, Translations from Drawing to Building and Other Essays. Cambridge (Mass.): MIT Press, 194-231. This article was first published in 9H, 8 (1989), 120-147.

Frampton, K. (Ed.). (1978). A New Wave of Japanese Architecture. New York (NY): Institute for Architecture and Urban Studies.

Frampton, K. (1986). Ukiyo-e and the Art of Toyo Ito. Space Design, 264 (September), 144-147.

Frampton, K. (Ed.) (1992) David Chipperfield. Barcelona: Editorial Gustavo Gili.

Hamashima, M. (1992). Sekkeizu ga kataru kokenchiku no sekkai. [The World of Old Architecture Told in Design Drawings.] Tokyo: Shokokusha.

Hayashiya T., Nakamura, M. \& Hayashiya, S. (1974). Japanese Arts and the Tea Ceremony. Translated and adapted by J. P. Macadam. New York (NY): Weatherhill \& Tokyo: Heibonsha.

Ito, T. (1978a). The Thin Façade. The Japan Architect (September), 19-21. 
Ito, T. (1978b). Collage and Superficiality in Architecture. In Frampton, K. (Ed.) (1978). A New Wave of Japanese Architecture. New York (NY): Institute for Architecture and Urban Studies, 68-69.

Ito, T. (2001). Dividing vs. Making Continuous. In Toyo Ito: Sendai Mediatheque, Miyago, Japan, 1995-2000 (GA Detail 2). Tokyo: ADA Edita.

Ito, T. (2005). Interview with Toyo Ito: Invisible Process. Architecture + Urbanism (417), 16.

Ito, T. (2006). The New "Real": Toward Reclaiming Materiality in Contemporary architecture. In A. Suzuki \& A. Imafuji (Eds.) (2006). Toto Ito: The New "Real" in Architecture. Tokyo: Toyo Ito Exhibition Executive Ctte, 30-44.

Ito, T. (2009). In Search of a New Architectural Order. In Toyo Ito. London: Phaidon Press, 7-9.

Ito., T. (2010a). Ito toyo tokuhon - 2010 [Toyo Ito Reader - 2010]. Tokyo: ADA Edita.

Ito, T. (2010b). (2010, January 14). Pers. comm. to the author.

Itoh, T. (1972). Traditional Domestic Architecture of Japan. Translated by R. L. Gage. New York (NY) \& Tokyo: Weatherhill / Heibonsha.

Itoh, T. \& Futagawa, Y. (1969). The Elegant House: Traditional Sukiya Architecture. New York (NY) \& Tokyo: Walker / Weatherhill.

Le Corbusier. (1946). Towards a New Architecture. Translated by F. Etchells. London: The Architectural Press.

Matsuoka, S. (Ed.) (1978). Ma: Espace-Temps du Japon. [Ma: Space-time in Japan.] Paris: Musée des Arts Décoratifs.

Nakamura, M. (1998). Chashitsu no rekishi: Kizo ga wakaru $Q+A$. [The History of Teahouses.] Kyoto: Tankosha.

Nakamura, M. (Ed.) (2005). Chashitsu okoshiezu no miryoku [The attraction of folding drawings]. Fukui, Japan: Fukui shimbunsha.

Nishi, K. \& Hozumi, K. (1983). What is Japanese Architecture? Translated, adapted and with an introduction by H. Mack Horton. Tokyo, New York (NY) \& San Francisco (Ca.): Kodansha.

Okawa, N. (1975). Edo Architecture: Katsura and Nikko. Translated by A. Woodhull and A. Miyamoto. New York (NY): Weatherhill \& Tokyo: Heibonsha.

Õta, H. (Ed.). (1972). Traditional Japanese Architecture and Gardens. Translated by Kirishiki Shinjiro. Yokohama: Kokusai Bunka Shinkõkai.

Taki, K. (2006). Life and Technology. In A. Suzuki \& A. Imafuji (Eds.) (2006). Toto Ito: The New "Real" in Architecture. Tokyo: Toyo Ito Exhibition Executive Ctte, 9-21.

Takiguchi, N. (2005). The Design of Small Things: An Interview with Toyo Ito. Unpublished paper.

Wilton-Ely, J. (1997), The Rise of the Professional Architect in England. In S. Kostof (Ed.), The Architect: Chapters in the History of the Profession. New York (NY): Oxford University Press. 